\title{
A Novel Method for Matching Reservoir Parameters Based on Particle Swarm Optimization and Support Vector Machine
}

\author{
Rongwang Yin $\mathbb{D}^{1,2}$ Qingyu Li, ${ }^{1}$ Peichao Li $\mathbb{D}^{3},{ }^{3}$ and Detang Lu $\mathbb{D}^{1}$ \\ ${ }^{1}$ School of Engineering Science, University of Science and Technology of China, Hefei 230026, China \\ ${ }^{2}$ Department of Basic Teaching and Experiment, Hefei University, Hefei 230601, China \\ ${ }^{3}$ School of Mechanical and Automotive Engineering, Shanghai University of Engineering Science, Shanghai 201620, China \\ Correspondence should be addressed to Peichao Li; wiselee18@163.com and Detang Lu; dtlu@ustc.edu.cn
}

Received 4 November 2019; Revised 12 February 2020; Accepted 19 February 2020; Published 29 April 2020

Academic Editor: Marco Pizzarelli

Copyright (c) 2020 Rongwang Yin et al. This is an open access article distributed under the Creative Commons Attribution License, which permits unrestricted use, distribution, and reproduction in any medium, provided the original work is properly cited.

When the reservoir physical properties are distributed very dispersedly, the matching precision of these reservoir parameters is not good. We propose a novel method for matching the reservoir physical properties based on particle swarm optimization (PSO) and support vector machine (SVM) algorithm. First, the data structure characteristics of the reservoir physical properties are analyzed. Then, the particle swarm differential perturbation evolution algorithm is used to cluster and characterize the reservoir physical properties. Finally, by using the SVM algorithm for feature reorganization and the least squares matching of the extracted reservoir physical properties, the feature quantity of the reservoir physical properties can be accurately mined and the pressure matching precision is improved. The experimental results show that employing the proposed method to analyze and sample the data characteristics of the physical properties of the reservoir is better. The extracted parameters can effectively reflect the physical characteristics of oil reservoirs. The proposed method has potential applications in guiding the exploration and development of oil reservoirs.

\section{Introduction}

With the continuous development of oil and gas industry, higher requirements are imposed on the oilfield exploitation process. Thereby, in oilfield exploitation, it is necessary to analyze the reservoir physical properties more accurately. The matching and feature extraction of the reservoir physical properties provide a basis for improving the exploration and production efficiency of the oilfields. Studies of the reservoir physical properties and dynamic analysis methods are of great significance, and the related data analysis methods are investigated by many researchers [1-7]. Traditional methods for describing fluid flow in porous media are theoretical-empirical models such as Navier-Stokes, Darcy, Brinkman, and Darcy-Forchheimer. Most commonly, in order to estimate the reservoir physical properties, $\log$ data can be used. One benefit of using logging data is that it provides a continuous distribution throughout a specific interval [8-16].
The reservoir physical properties are essential for the calculation of fluid flow in oil and gas reservoirs. In other words, reservoir simulation and modeling cannot be performed unless the reservoir physical properties are available [17]. Reservoir simulation is often used to predict reservoir performance under different scenarios. For accurate simulation, it is necessary to reduce or minimize the uncertainty involved in the parameters. The main factor leading to the uncertainty of reservoir performance prediction is to accurately estimate the reservoir fluid properties [18-20]. There is no doubt that the data of the reservoir physical properties are valuable and necessary input data in the reservoir simulators. It is necessary and essential to accurately determine their values in each reservoir study.

Usually, the reservoir physical properties are determined in the laboratory [21]. In general, laboratory methods fall into two broad categories of steady state and nonsteady state [22]. Measurements of the reservoir physical properties are often very sensitive, time consuming, and expensive [23]. 
Therefore, researchers are more willing to obtain these data from other fast and accurate methods. Empirical correlations and analytical mathematical models are widely used to predict the reservoir physical properties [24, 25]. Purcell introduced the first analytical mathematical model in 1949 to estimate the relative permeability of water-oil and oil-oil systems using capillary pressure data [26]. In 1954, Corey developed an empirical study to estimate the relative permeability of oil and gas systems based on large relative permeability measurements based on a number of cores from several formations [27]. In 1982, Lomeland et al. developed an empirical correlation for water-oil and natural gas-oil systems which takes into account the effects of wettability and rock type [28]. Considering the effects of pressure, fluid viscosity, and flow rate, $\mathrm{Xu}$ et al. proposed a stage of a pressure gradient water-oil system that takes into account the relative permeability of water affected by displacement [29].

In recent years, intelligent systems such as the least squares SVM (LSSVM), the adoptive neurofuzzy interface system (ANFIS), and the artificial neural networks (ANN) have been used in rock physics. The work carried out by Mohamadi-Baghmolaei et al. was used to predict the gas compressibility factors [30].

Intelligent algorithms are widely used in the field of reservoirs. Baghban et al. attempted to predict dew points using ANFIS and LSSVM models [31]. Ahmedi et al. used evolving simple-to-use method to predict oil-water relative permeability [32]. Ahmadi successfully employed the LSSVM model [33] to model the gas-oil relative permeability. In addition, fuzzy logic modeling has been successfully applied to the permeability prediction of porous media. An example of using this technique in permeability prediction is performed by Ilkhchi et al. [34], where they incorporated fuzzy IF-THEN rules into neural networks to estimate reservoir properties [34].

It turns out that machine learning has to do with solving the most challenging industrial problems. The petroleum industry is always looking for high-performance predictive models, so this new learning method is greatly needed. Minor improvements in the prediction of the reservoir physical properties may have a positive impact on the success of exploration, drilling, and overall reservoir management. With the successful application of learning modeling in other fields, the petroleum industry urgently needs this new modeling method [35].

Various sensor-based data are being generated and obtained in the petroleum industry. Since the data obtained through these systems may involve high dimensions, hybrid machine-learning methods are best suited to extract useful knowledge from them without affecting expert opinion and model performance. The hybrid-learning model can combine different architectures of its basic model, different data sampling methods, and various optimization parameters obtained from different experts to optimize the estimation and prediction of the reservoir physical properties [36]. However, the application of computational intelligence in the petroleum industry is mainly limited to artificial neural networks and fuzzy logic. There is very little work in the field of hybrid computational intelligent modeling, and there is almost no application of ensemble models [37].

It is necessary to adopt a hybrid learning method to improve the accuracy of prediction so as to further improve the subsequent success rate of exploration and drilling. The marginal increase in prediction accuracy can increase the efficiency of producing petroleum resources with less time and efforts. Based on all these reasons, this paper proposes a method based on PSO and SVM to match the reservoir physical properties.

\section{Characteristics Analysis and Data Clustering Pretreatment}

2.1. Data Structure Feature Analysis. In order to achieve the optimal matching of the reservoir physical parameters, it is first necessary to analyze the data structure characteristics and distributed structure model of the reservoir physical parameters. The physical property parameters of the reservoirs can effectively reflect the physical information of the reservoir information. The collected permeability, well storage, skin, fracture radius, half length of fracture, and other parameter information are used as important data sources for the reservoir physical parameters. Through the analysis of the reservoir properties, the oil and gas field development and design will be guided to improve the final mining of the oilfields. The data structure model under the distributed structure of the reservoir physical property parameters is described as

$$
\begin{aligned}
C & =\operatorname{Min}\left\{\max \left(C_{i}\right)\right\} x_{i}(k)+s\left(\frac{x_{j}(k)-x_{i}(k)}{\left\|x_{j}(k)-x_{i}(k)\right\|}\right), \\
\sum_{j^{\prime}=1}^{p^{\prime}} Z_{i, j, j^{\prime}} & =1, \quad \forall i \in(1, n) \forall j \in\left(1, n_{i}\right) j \in N_{i}(k), N_{i}(k) \\
& =\left\{\left\|x_{j}(k)-x_{i}(k)\right\|<r_{d}(k)\right\},
\end{aligned}
$$

where $C_{i}$ represents a generalized likelihood feature vector of the property parameter data packet and $Z_{i, j, j^{\prime}}$ represents the interference eigenvector in discrete sample acquisition of reservoir physical parameters. Through the abovementioned analysis, the prior data $\left\{x_{i}\right\}_{i=1}^{N}$ of the reservoir physical property parameter test is mapped to the high-order vector space [38-42]. Assuming that there are $n$ samples in the reservoir physical property test set $S$, the following two functions are constructed to represent the multibeam feature vector of the reservoir physical parameters:

Schwefel function:

$$
f_{1}(x)=\sum_{i=1}^{n}\left(\sum_{j=1}^{i} x_{j}\right)^{2} .
$$

Rosebrock function: 


$$
f_{2}(x)=\sum_{i=1}^{n-1} 100 \times\left(x_{i+1}-x_{i}^{2}\right)^{2}+\left(1-x_{i}\right)^{2} .
$$

Assuming that, in the $D$-dimensional multibeam search space, there are $m$ particles composing a population, and the environmental data collected by the physical parameters satisfy

$$
Q^{\prime}=\left[\begin{array}{cccc}
0 & y_{1} & \cdots & y_{n} \\
y_{1} & Q_{11} & \cdots & Q_{1 n} \\
\vdots & \vdots & \ddots & \vdots \\
y_{n} & Q_{n 1} & \cdots & Q_{n n}
\end{array}\right] \stackrel{\operatorname{def}}{=}\left[\begin{array}{cc}
0 & y^{T} \\
y & Q
\end{array}\right]
$$

According to the abovementioned assumptions, in the case of data set characteristics, the classification matrix $Q$ of the property parameter is positive, then the inverse matrix of the state transition matrix $Q$ of these parameters is $Q^{-1}$, and the state transition matrix $Q^{-1}$ can effectively react to the reservoir data structure characteristics of physical parameters; the feature decomposition process is

$$
\left[\begin{array}{cc}
0 & -y^{T} Q^{-1} \\
0 & I_{n}
\end{array}\right]\left[\begin{array}{ll}
0 & y^{T} \\
y & Q
\end{array}\right]=\left[\begin{array}{cc}
-y^{T} Q^{-1} & 0 \\
y & Q
\end{array}\right] \text {, }
$$

with

$$
\operatorname{det}\left(Q^{\prime}\right)=\operatorname{det}(Q) \cdot\left(-y^{T} Q^{-1}\right) \neq 0
$$

Through the abovementioned analysis, the data structure characteristics of the parameters are realized. Based on this, the feature extraction and data clustering mining processing are carried out to realize the matching analysis of the reservoir physical parameters.

2.2. Parameter Clustering Preprocessing. Based on the abovementioned analysis of the data structure characteristics of the reservoir physical parameters, the particle swarm differential perturbation evolution algorithm is used to cluster the reservoir physical parameters. The PSO algorithm is a new intelligent optimization algorithm proposed by Kennedy and Eberhart in 1995. The particle swarm differential perturbation evolution is used to construct the autoregressive equation expression of reservoir physical property parameters in high dimensional space:

$$
f(x)=\omega^{T}(\phi)_{X}+b,
$$

where $\omega$ is the weighted value of the individual with the highest fitness and $b$ is expressed as the deviation vector. The probability distribution of the reservoir physical property parameter in the particle swarm individual is $P_{i}=\left(p_{i 1}\right.$, $\left.p_{i 2}, \ldots, p_{i}{ }_{D}\right)$.

In the process of particle swarm evolution, the degree of difference between individuals increases. By extracting the difference features, the position of the $i$ th particle at the moment is obtained:

$$
x_{i}(k+1)=x_{i}(k)+s\left(\frac{x_{j}(k)-x_{i}(k)}{\left\|x_{j}(k)-x_{i}(k)\right\|}\right) \text {, }
$$

where

$$
j \in N_{i}(k), \quad N_{i}(k)=\left\{\left\|x_{j}(k)-x_{i}(k)\right\|<r_{d}(k)\right\} .
$$

The constructed value loss function is used to represent the clustering feature vector of the reservoir physical property parameters, and the initial cluster center $E$ is described in the particle swarm population as

$$
E=\sum_{j=1}^{q} \frac{E_{j}}{q \times k}
$$

where

$$
E_{j}=\sum_{k} \varepsilon_{k}^{2}=\sum_{k}\left(d_{k}-c_{k}\right)^{2}
$$

The designed error back propagation factor and chaotic map are used to optimize the particle swarm differential perturbation so that the reservoir physical parameters have better adaptability in cluster training. At this time, the optimization model of reservoir physical parameter clustering is

$$
\min _{\omega, h, \zeta_{l}, \zeta_{l}^{*}}=\frac{1}{2} \omega^{T} \omega+c \sum_{i=1}^{l}\left(\zeta_{l}+\zeta_{l}^{*}\right)
$$

where $\zeta_{l}$ and $\zeta_{l}^{*}$ represent the slack variables produced by the posterior probability $p\left(x_{0}\right) ; \xi$ is the insensitive loss function in the clustering process of particle swarm data; and $c$ represents the compromise of the fitting precision of data samples. The clustering preconditioning of reservoir physical property parameters based on particle swarm differential perturbation evolution is realized.

\section{Algorithm Improvement}

3.1. Feature Extraction. Based on the analysis of data structure characteristics and data clustering pretreatment of reservoir physical parameters, the improved algorithm for reservoir physical property parameters matching is designed. The traditional method uses the fuzzy $C$-means clustering matching algorithm to match the reservoir physical property parameters. When the dispersed characteristics of the reservoir physical property parameters are large, the matching accuracy of the reservoir physical parameters is not good. In order to overcome the defect of traditional methods, this paper proposes a method based on PSO and SVM algorithm for reservoir physical property parameters. Based on the particle swarm differential perturbation evolution algorithm for clustering of reservoir physical property parameters, feature extraction is performed, and the weights of each particle in the feature extraction of reservoir physical parameters are calculated: 


$$
\widetilde{w}_{k}^{i}=\widetilde{w}_{k-1}^{i} \frac{p\left(z_{k} / \widetilde{x}_{k}^{i}\right) p\left(\widetilde{x}_{k}^{i} / x_{k-1}^{i}\right)}{q\left(\widetilde{x}_{k}^{i} / x_{k-1}^{i}\right)}
$$

During the search process, the particle swarms perform minimum feature space recombination on the extracted reservoir physical parameters and normalize the weight values of each particle:

$$
\widetilde{\widetilde{w}}_{k}^{i}=\frac{\widetilde{w}_{k}^{i}}{\sum_{i=1}^{N} w_{k}^{i}} .
$$

The larger the $c$ value, the higher the matching precision of the reservoir parameters. The estimated function is obtained by adaptive least squares estimation by monitoring the threshold value of the reservoir parameters:

$$
f(x)=\sum_{i=1}^{l}\left(a_{i}+a_{i}^{*}\right) k\left(x-x_{i}\right)+b .
$$

Using the particle swarm differential perturbation search method, the feature information is continuously searched in the global scope. The expressions of the feature extraction results of the reservoir physical parameters in the optimal and global search space are

$$
\begin{aligned}
& K\left(x_{i}, x_{j}\right)=\left\langle x_{i}, x_{j}\right\rangle, \\
& \left.K\left(x_{i}, x_{j}\right)=\left(<x_{i}, x_{j}\right\rangle+1\right)^{d}, \\
& K\left(x_{i}, x_{j}\right)=\exp \left(\frac{\left\|x_{i}-x_{j}\right\|^{2}}{2 \sigma^{2}}\right) .
\end{aligned}
$$

After the operation reaches convergence, the most adaptive individual in the entire particle population is the optimal approximate solution needed. Thus, the feature extraction of the reservoir physical parameters is realized, which provides an accurate data basis for precisely matching and information mining of reservoir physical parameters.

3.2. Parameter Matching Based on SVM. The SVM model is used to perform feature reorganization and least squares matching on the extracted reservoir physical parameters to realize accurate mining of feature quantities. Combined with the data characteristics of the reservoir physical parameters, the standard SVM model is assumed to be

$$
\min _{0 \leq \alpha_{i} \leq c} W=\frac{1}{2} \sum_{i, j=1}^{l} y_{i} y_{j} \alpha_{i} \alpha_{j} K\left(x_{i}, x_{j}\right)-\sum_{i=1}^{l} \alpha_{i}+b\left(\sum_{i=1}^{l} y_{j} \alpha\right) \text {. }
$$

where $\left(x_{i}, x_{j}\right)$ is the data feature extraction sample and $b$ is the Lagrange operator, and the vector feature sample set matched to the reservoir physical property parameters is

$$
S=\left\{\left(x_{1}, x_{1}\right), \ldots,\left(x_{l}, x_{l}\right)\right\}
$$

where $x_{i}=\left(x_{i 1}, x_{i 2}, \ldots, x_{i}{ }_{D}\right)$ is the eigenvector; the firstorder partial derivative of the SVM model $W$ is calculated, and the characteristic discriminant of the least squares matching of the reservoir physical property parameters under the standard SVM is

$$
G_{i}=\sum_{j} \alpha_{j} y_{i} y_{j} K\left(x_{i}, x_{j}\right)+y_{i} b-1 \text {. }
$$

In the reservoir physical property parameters space, by adaptively adjusting the weight vector $\alpha_{c}$, the covariance and the adaptive spectral peak weighted search method are used to solve the normalized vector of the matching center.

When

$$
\alpha=\left(\alpha_{1}, \alpha_{2}, \ldots, \alpha_{n}\right) \neq 0,
$$

we have

$$
\alpha^{T} Q \alpha=\sum_{i=1}^{n} \sum_{j=1}^{n} \alpha_{i} \alpha_{j} Q_{i j} \geq 0 .
$$

In the sample update process of the SVM set $S_{s}$, there are $\forall i \in S_{s}, \beta_{i}^{c} \neq \pm \infty$, and $\forall i \in S-S_{s}, \gamma_{i}^{c} \neq \pm \infty$. For the $\forall i \in S_{s}$ of the parameter, the time window width in the direction of the gradient descent is

$$
\begin{aligned}
\beta_{i}^{c} & =-\sum_{k \in S_{s}} R_{i k} Q_{k c}-R_{i 1} y_{c} \\
& =-\frac{1}{\operatorname{det}\left(Q^{\prime}\right)}\left(\sum_{k \in S_{s}}(-1)^{i+k} \operatorname{det}\left(Q_{\backslash k i}^{\prime}\right) Q_{k c}+y_{c}(-1)^{i+1} \operatorname{det}\left(Q_{i 1}^{\prime}\right)\right) .
\end{aligned}
$$

In order to reflect the diversity characteristics of the particle population during the data matching process, the matching update is performed in the finite step adjustment. When the set $S_{s}$ satisfies

$$
\begin{aligned}
Q^{-} \cdot R^{-} & =Q^{-} \cdot R_{t t}-\frac{Q^{-}}{R_{t t}}\left(R_{* t} \cdot R_{* t}\right)_{\backslash t t} \\
& =Q^{-} \cdot R_{t t}+\left(R_{* t} \cdot R_{* t}\right)_{\backslash t t}=I .
\end{aligned}
$$

As the sample size increases, the parameters generate $X_{1}$ and $X_{2}$ as finite sequences. Under the control of the SVM model, the matched output results are

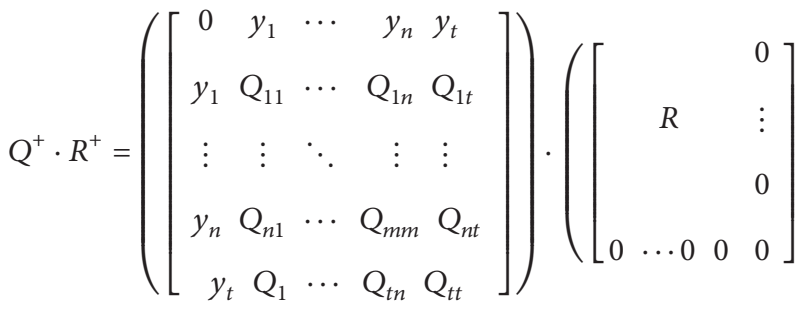

$$
\begin{aligned}
& \left.+\frac{1}{\gamma_{t}^{t}}\left[\begin{array}{c}
\beta^{t} \\
\beta_{1}^{t} \\
\vdots \\
\beta_{n}^{t} \\
1
\end{array}\right] \cdot\left[\begin{array}{c}
\beta^{t} \\
\beta_{1}^{t} \\
\vdots \\
\beta_{n}^{t} \\
1
\end{array}\right]^{T}\right]=\left[\begin{array}{ll}
I & 0 \\
0 & 1
\end{array}\right]
\end{aligned}
$$




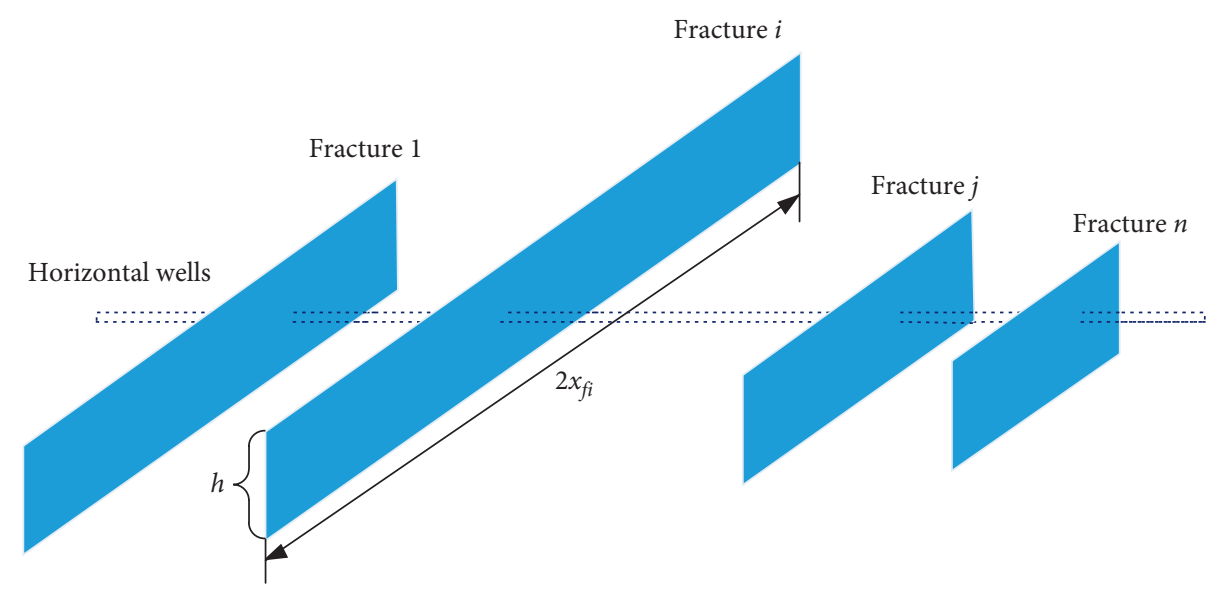

FIGURE 1: Schematic diagram of horizontal well with multistage fracturing.

The velocity of the particle population is $V_{i}=\left(v_{i 1}\right.$, $\left.v_{i 2}, \ldots, v_{i D}\right)^{T}$, and the position is $X_{i}=\left(x_{i 1}, x_{i 2}, \ldots, x_{i D}\right)^{T}$. Through the SVM algorithm, the initial reservoir parameters converge to the global optimal, which indicates that the proposed method has stability and global convergence.

\section{A Case Study}

In order to test the performance of the proposed method in the optimization and matching of reservoir physical property parameters, a case study is carried out. The underground reservoir is located in western China, and the well is a multistage fracturing horizontal well. The stratum is a rectangular fully enclosed reservoir with homogeneous formation. The reservoir fluid is the tight oil and the fluid flow satisfies Darcy's law. Horizontal well position, fracture locations at all levels, fracture shapes, and reservoir boundaries are shown in Figure 1.

The number of wells in the actual production process is far from meeting the demand for the number of samples. Taking the multistage fracturing of horizontal wells as an example, the parameters affecting the curve shape and calculation results mainly include permeability, well storage, skin, half length of fractures, and the number of fractures. Even if 100 basic values are selected for each parameter, random matching is adopted, and the number of combinations obtained reaches $10^{10}$ groups, and the spatial uniformity of the parameter group cannot be guaranteed. Matching using the method proposed in this paper can obtain the high quality samples, thus improving the accuracy of the matching. The setting of each parameter value used in the algorithm is as follows. The distributed attenuation factor of the matching center is $\lambda=0.25$, the population size of the particle group is set to 20 , the matching threshold is set to $\mu=10$, the parameter $G_{\max }=30, D=12, C=3$, and $N P=30$, the particle swarm differential perturbation range is set to $\beta=0.001$, and the crossover probability of the particle swarm is $[0,1]$.

One of the important concepts for describing multiphase flow in porous media is permeability. In order to verify the effectiveness of the algorithm, the genetic algorithm (GA),

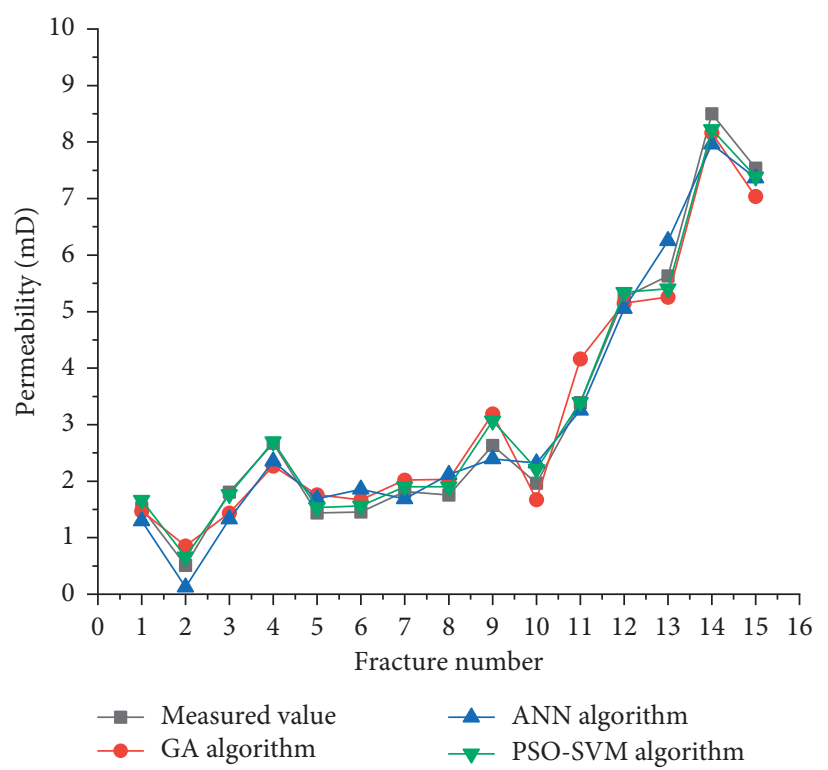

FIgURE 2: Prediction of permeability of different algorithms.

ANN, and the method proposed in this paper were used to perform matching on the permeability data. The results obtained are shown in Figure 2. The permeability prediction results of the three algorithms are shown in Table 1. As can be seen from Table 1, the Root Mean Square Error (RMSE) of GA is 0.384, the RMSE of ANN is 0.35, and the RMSE of PSO-SVM is 0.183 . It can be known from the prediction results that the overall performance of the PSO-SVM method is better and the prediction results are more accurate.

After obtaining the predicted values of all the physical parameters, they are imported into the reservoir model and the formation pressure is calculated. The comparison between the calculated results and the measured data is shown in Figure 3. It shows that the measured pressure and the calculated pressure match well with an average error of $2.8 \%$, which is within an acceptable range.

To further verify the accuracy of the predicted data, the obtained reservoir parameters were introduced into the 
TABLE 1: Permeability prediction results of different algorithms.

\begin{tabular}{|c|c|c|c|c|}
\hline Fracture number & Measured value & GA & ANN & PSO-SVM \\
\hline 1 & 1.52908 & 1.4727 & 1.2943 & 1.663 \\
\hline 2 & 0.50653 & 0.85352 & 0.124 & 0.66 \\
\hline 3 & 1.8074 & 1.43808 & 1.332 & 1.763 \\
\hline 4 & 2.671 & 2.272 & 2.354 & 2.701 \\
\hline 5 & 1.4365 & 1.7597 & 1.687 & 1.532 \\
\hline 6 & 1.4522 & 1.66732 & 1.854 & 1.564 \\
\hline 7 & 1.81824 & 2.02017 & 1.687 & 1.9 \\
\hline 8 & 1.7561 & 2.0329 & 2.114 & 1.902 \\
\hline 9 & 2.632 & 3.1921 & 2.394 & 3.065 \\
\hline 10 & 1.966 & 1.6739 & 2.321 & 2.211 \\
\hline 11 & 3.389 & 4.1665 & 3.256 & 3.395 \\
\hline 12 & 5.25 & 5.14845 & 5.054 & 5.341 \\
\hline 13 & 5.6328 & 5.25905 & 6.254 & 5.406 \\
\hline 14 & 8.5 & 8.16 & 7.965 & 8.225 \\
\hline 15 & 7.539 & 7.037 & 7.365 & 7.385 \\
\hline
\end{tabular}

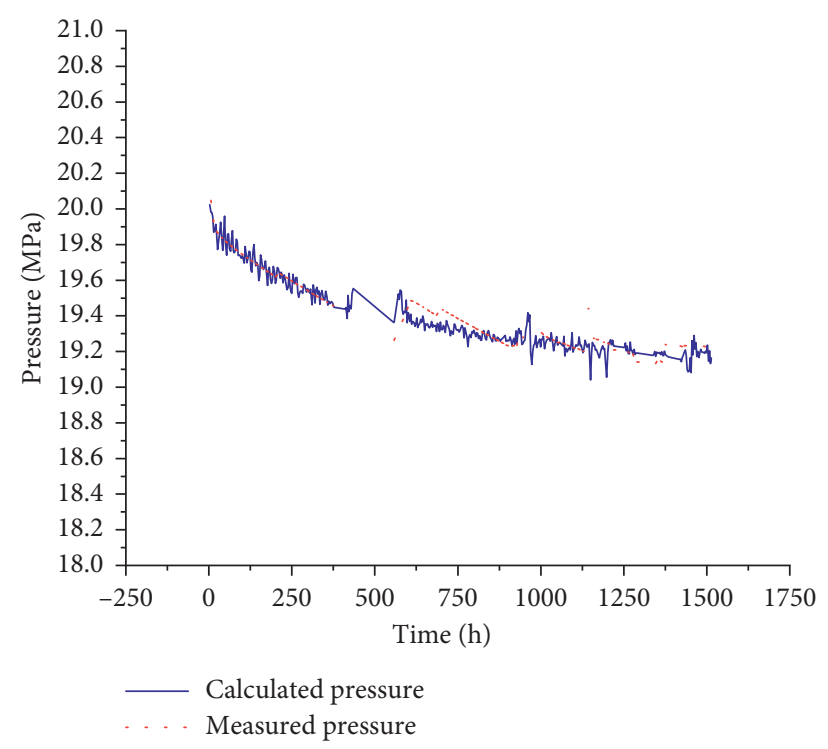

FIgURE 3: History match figure of bottom hole pressure.
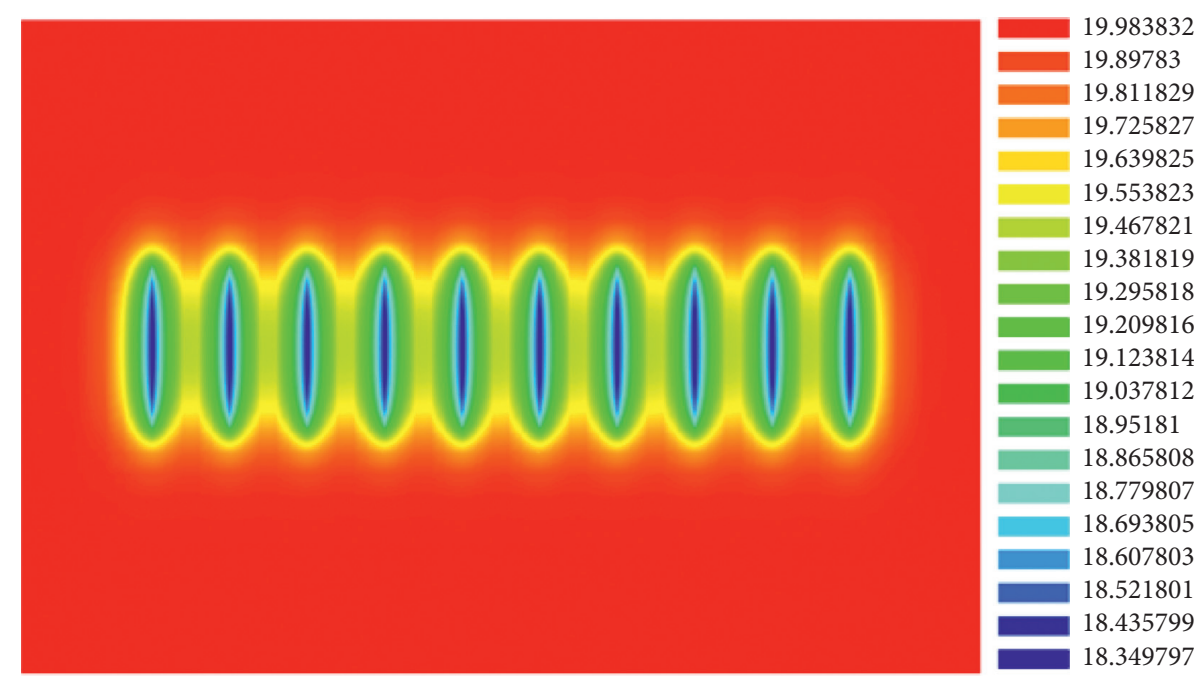

Figure 4: Formation pressure distribution at $120 \mathrm{~h}$. 

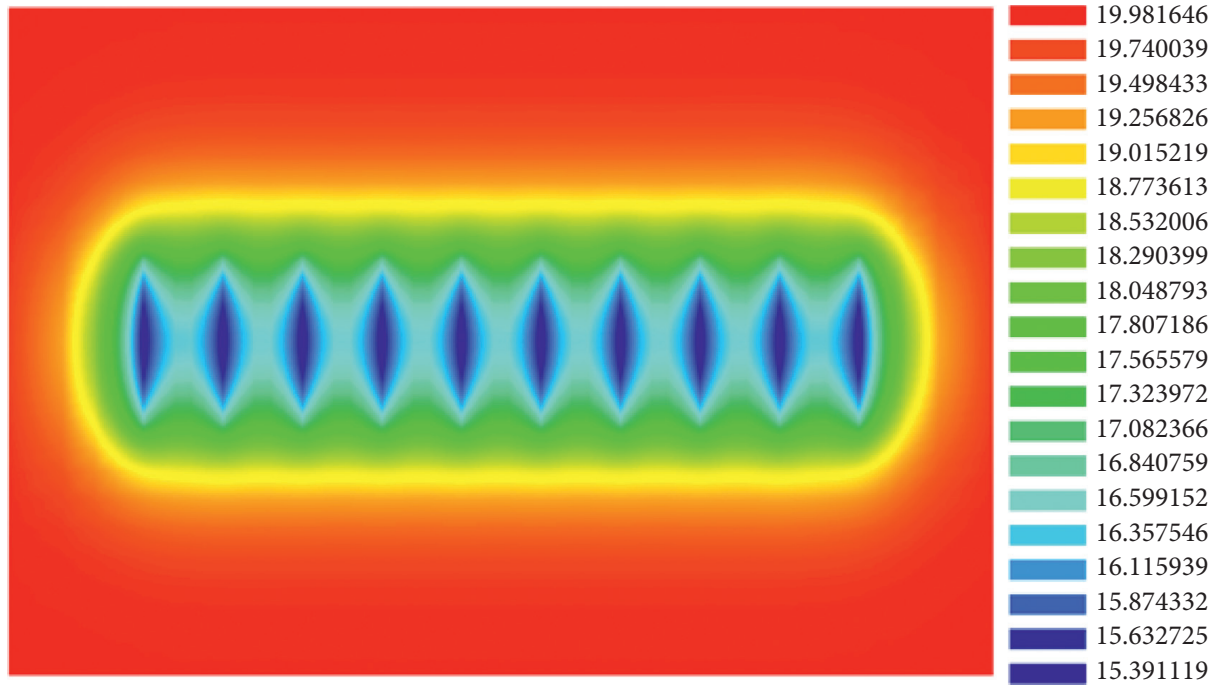

Figure 5: Formation pressure distribution at $630 \mathrm{~h}$.
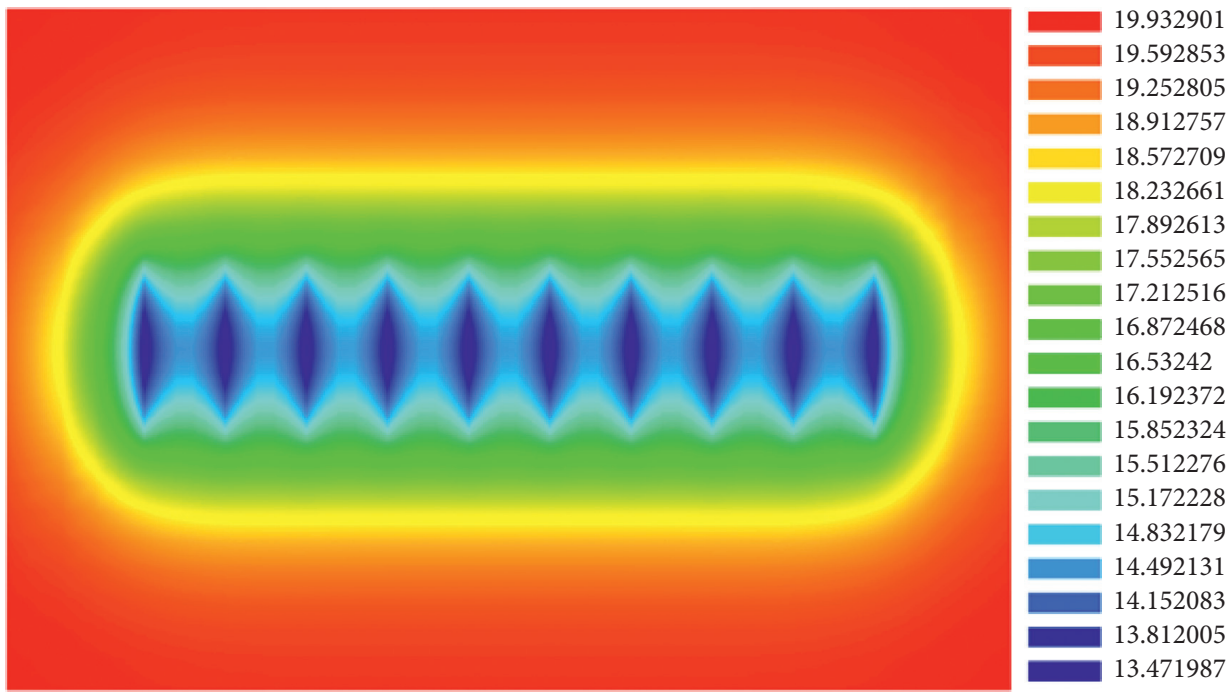

FIgURE 6: Formation pressure distribution at $1120 \mathrm{~h}$.
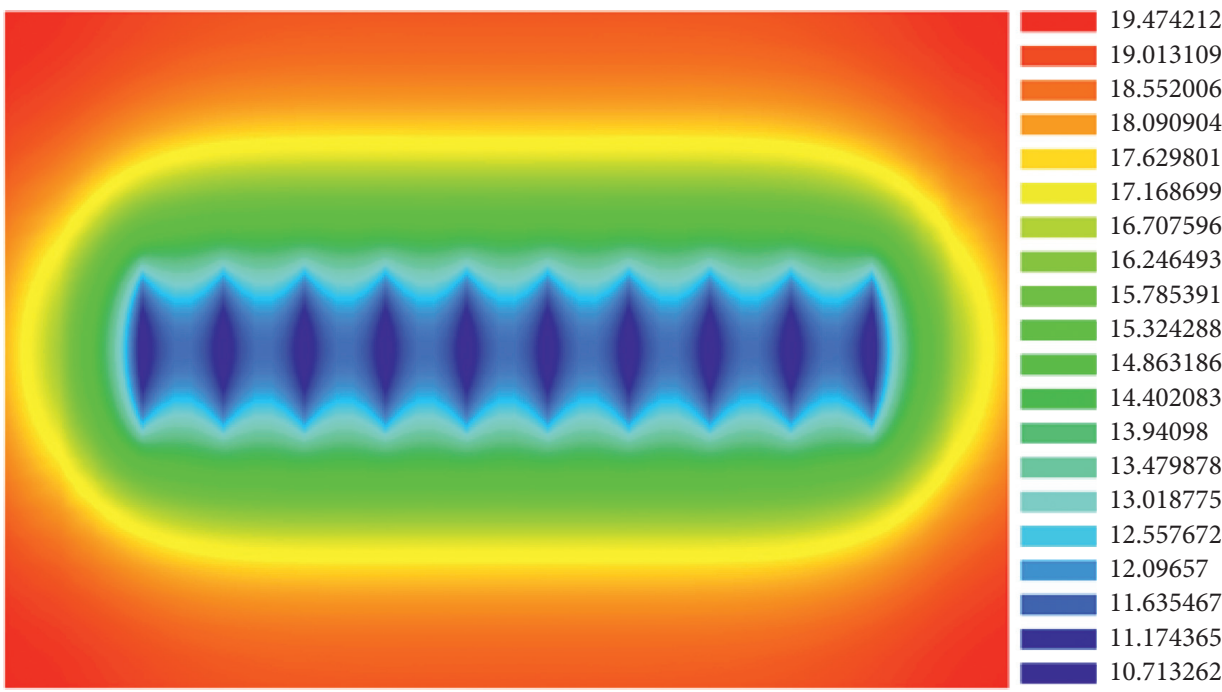

FIGURE 7: Formation pressure distribution at $2160 \mathrm{~h}$. 

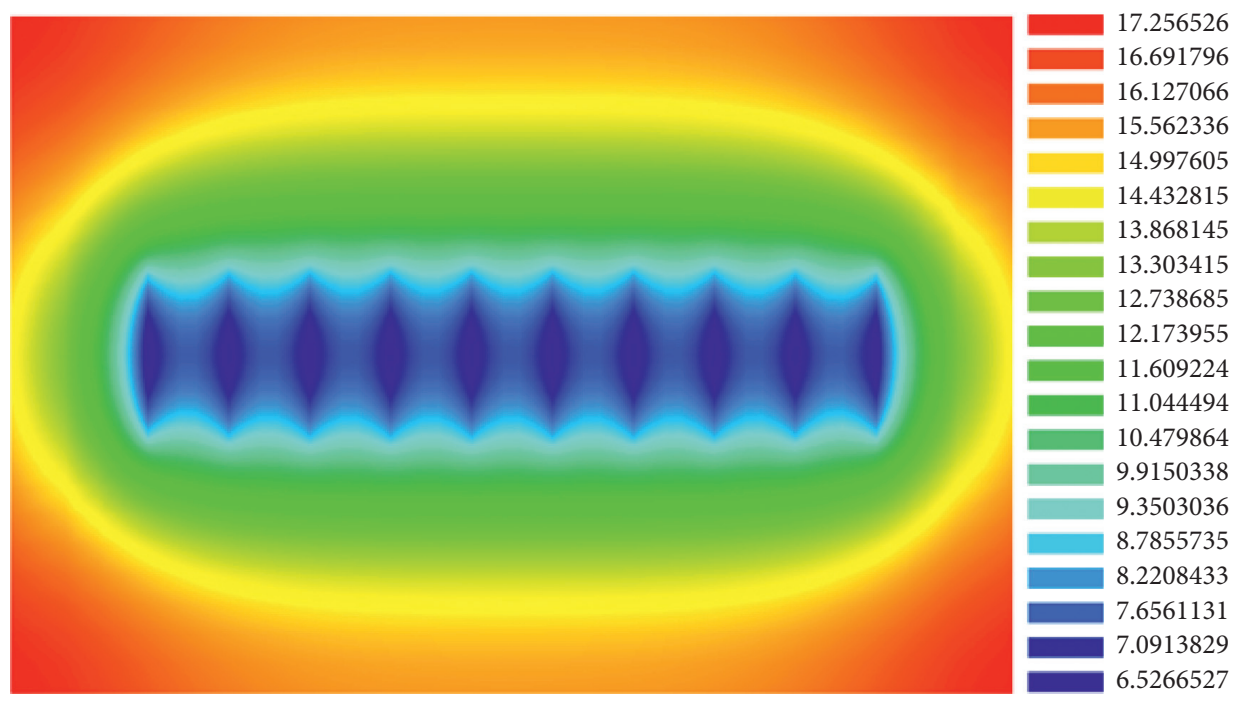

FIGURE 8: Formation pressure distribution at $4320 \mathrm{~h}$.

example well to obtain the bottom hole pressure distribution, and the results are shown in Figures 4-8. Figures 4-8 are plots of bottom hole pressure at 120 hours, 630 hours, 1120 hours, 2160 hours, and 4230 hours, respectively.

The flow in Figure 4 is in the linear flow phase and the flow is concentrated near the crack. From Figures 5-7, the flow gradually expands outward, and the flow state appears as a linear flow to a radial flow transition phase. In Figure 8, the flow is about to reach the boundary, where the flow state is a mixed flow of radial flow and boundary control flow. The flow patterns are in good agreement with seepage laws from Figures $4-8$. The results of the pressure distribution are in accordance with expectations, which also verify the correctness of the algorithm.

\section{Conclusions}

In this paper, a matching method for reservoir physical property parameters based on PSO and SVM algorithm is proposed. The main conclusions can be summarized as follows:

(1) The obtained physical parameters have better spatial uniformity and can truly reflect the reality of underground reservoirs

(2) The matching accuracy of the formation pressure is within the allowable error range

(3) The formation pressure matching by the optimization algorithm can better meet the computational requirements of complex nonlinearities

\section{Data Availability}

The data used to support the findings of this study are available from the corresponding author upon request.

\section{Conflicts of Interest}

The authors declare that they have no conflicts of interest.

\section{Acknowledgments}

This work was supported by the National Natural Science Foundation of China (Grant no. 41672114) and National Science and Technology Major Project (Grant no. 2017ZX05009005-002).

\section{References}

[1] T. A. Cousins, B. Ghanbarian, and H. Daigle, "Three-dimensional lattice Boltzmann simulations of single-phase permeability in random fractal porous media with rough pore-solid interface," Transport in Porous Media, vol. 122, no. 3, pp. 527-546, 2018.

[2] D. Vogler, R. R. Settgast, C. Annavarapu, C. Madonna, P. Bayer, and F. Amann, "Experiments and simulations of fully hydromechanically coupled response of rough fractures exposed to high-pressure fluid injection," Journal of Geophysical Research: Solid Earth, vol. 123, no. 2, pp. 1186-1200, 2018.

[3] B. Han and X. Bian, "A hybrid PSO-SVM-based model for determination of oil recovery factor in the low-permeability reservoir," Petroleum, vol. 4, no. 1, pp. 43-49, 2018.

[4] S. Chi, S. Ni, and Z. Liu, "Back analysis of the permeability coefficient of a high core rockfill dam based on a RBF neural network optimized using the PSO algorithm," Mathematical Problems in Engineering, vol. 2015, Article ID 124042, 15 pages, 2015.

[5] K. O. Akande, T. O. Owolabi, S. O. Olatunji, and A. AbdulRaheem, "A hybrid particle swarm optimization and support vector regression model for modelling permeability prediction of hydrocarbon reservoir," Journal of Petroleum Science and Engineering, vol. 150, pp. 43-53, 2017.

[6] A. Mortazavi and M. Ahmadi, "Applying an optimized low risk model for fast history matching in giant oil reservoir," Kuwait Journal of Science, vol. 46, no. 1, 2019.

[7] H. Jung, H. Jo, S. Kim, K. Lee, and J. Choe, "Geological model sampling using PCA-assisted support vector machine for reliable channel reservoir characterization," Journal of Petroleum Science and Engineering, vol. 167, pp. 396-405, 2018.

[8] F. Anifowose, A. Abdulraheem, and A. Al-Shuhail, "A parametric study of machine learning techniques in 
petroleum reservoir permeability prediction by integrating seismic attributes and wireline data," Journal of Petroleum Science and Engineering, vol. 176, pp. 762-774, 2019.

[9] X. Wang, B. Zhang, F. Li, J. Qi, and B. Bai, "Seismic timefrequency decomposition by using a hybrid basis-matching pursuit technique," Interpretation, vol. 4, no. 2, pp. T239T248, 2016.

[10] H. Bazargan, M. Christie, A. H. Elsheikh, and M. Ahmadi, "Surrogate accelerated sampling of reservoir models with complex structures using sparse polynomial chaos expansion," Advances in Water Resources, vol. 86, pp. 385-399, 2015.

[11] T. Jain, R. G. Patel, and J. Trivedi, “Application of polynomial chaos theory as an accurate and computationally efficient proxy model for heterogeneous steam-assisted gravity drainage reservoirs," Energy Science \& Engineering, vol. 5, no. 5, pp. 270-289, 2017.

[12] H. X. Vo and L. J. Durlofsky, "Regularized kernel PCA for the efficient parameterization of complex geological models," Journal of Computational Physics, vol. 322, pp. 859-881, 2016.

[13] K. Lee, S. Jung, T. Lee et al., "Use of clustered covariance and selective measurement data in ensemble smoother for threedimensional reservoir characterization[J]," Journal of Energy Resources Technology, vol. 139, no. 2, Article ID 022905, 2017.

[14] R. Y. Aliyarov and R. A. Ramazanov, "Prediction of multivariable properties of reservoir rocks by using fuzzy clustering," Procedia Computer Science, vol. 102, pp. 434-440, 2016.

[15] N. Mosavat, F. Torabi, and O. Zarivnyy, "Developing new corey-based water/oil relative permeability correlations for heavy oil systems," in Proceedings of the SPE Heavy Oil Conference-Canada. Society of Petroleum Engineers, Calgary, Alberta, Canada, June 2013.

[16] A. H. Sufi, H. J. Ramey Jr., and W. E. Brigham, “Temperature effects on relative permeabilities of oil-water systems," in Proceedings of the SPE Annual Technical Conference and Exhibition. Society of Petroleum Engineers, New Orleans, Louisiana, September 1982.

[17] S. M. Al-Fattah, "Empirical equations for water/oil relative permeability in Saudi sandstone reservoirs," in Proceedings of the Nigeria Annual International Conference and Exhibition. Society of Petroleum Engineers, Abuja, Nigeria, August 2003.

[18] K. Li and R. N. Horne, "Numerical simulation without using experimental data of relative permeability," Journal of Petroleum Science and Engineering, vol. 61, no. 2-4, pp. 67-74, 2008.

[19] P. H. Yang and A. T. Watson, "A bayesian methodology for estimating relative permeability curves," SPE Reservoir Engineering, vol. 6, no. 2, pp. 259-265, 1991.

[20] P. Xu, S. Qiu, B. Yu, and Z. Jiang, "Prediction of relative permeability in unsaturated porous media with a fractal approach," International Journal of Heat and Mass Transfer, vol. 64 , pp. 829-837, 2013.

[21] M. M. Honarpour, Relative Permeability of Petroleum Reservoirs: 0, CRC Press, Boca Raton, FL, USA, 2018.

[22] T. G. Sorop, S. K. Masalmeh, B. M. J. M. Suijkerbuijk et al., "Relative permeability measurements to quantify the low salinity flooding effect at field scale," in Proceedings of the Abu Dhabi International Petroleum Exhibition and Conference. Society of Petroleum Engineers, Abu Dhabi, UAE, November 2015.

[23] K. Li and R. N. Horne, "Comparison of methods to calculate relative permeability from capillary pressure in consolidated water-wet porous media," Water Resources Research, vol. 42, no. 6, 2006.

[24] M. Honarpour, L. F. Koederitz, and A. H. Harvey, "Empirical equations for estimating two-phase relative permeability in consolidated rock," Journal of Petroleum Technology, vol. 34, no. 12, pp. 905-912, 1982.

[25] M. N. Ibrahim and L. F. Koederitz, "Two-phase relative permeability prediction using a linear regression model," in Proceedings of the SPE Eastern Regional Meeting. Society of Petroleum Engineers, Morgantown, West Virginia, October 2000.

[26] W. R. Purcell, "Capillary pressures-their measurement using mercury and the calculation of permeability therefrom," Journal of Petroleum Technology, vol. 1, no. 2, pp. 39-48, 1949.

[27] A. T. Corey, "The interrelation between gas and oil relative permeabilities," Producers Monthly, vol. 19, no. 1, pp. 38-41, 1954.

[28] F. Lomeland, E. Ebeltoft, and W. H. Thomas, "A new versatile relative permeability correlation," in Proceedings of the International Symposium of the Society of Core Analysts, vol. 112, Toronto, Canada, 2005.

[29] J. Xu, C. Guo, R. Jiang, and M. Wei, "Study on relative permeability characteristics affected by displacement pressure gradient: experimental study and numerical simulation," Fuel, vol. 163, pp. 314-323, 2016.

[30] M. Mohamadi-Baghmolaei, R. Azin, S. Osfouri, R. Mohamadi-Baghmolaei, and Z. Zarei, "Prediction of gas compressibility factor using intelligent models," Natural Gas Industry B, vol. 2, no. 4, pp. 283-294, 2015.

[31] A. Baghban, M. Bahadori, J. Rozyn et al., "Estimation of air dew point temperature using computational intelligence schemes," Applied Thermal Engineering, vol. 93, pp. 10431052, 2016.

[32] M. A. Ahmadi, S. Zendehboudi, M. B. Dusseault, and I. Chatzis, "Evolving simple-to-use method to determine water-oil relative permeability in petroleum reservoirs," $P e$ troleum, vol. 2, no. 1, pp. 67-78, 2016.

[33] M. A. Ahmadi, "Connectionist approach estimates gas-oil relative permeability in petroleum reservoirs: application to reservoir simulation," Fuel, vol. 140, pp. 429-439, 2015.

[34] A. K. Ilkhchi, M. Rezaee, and S. A. Moallemi, "A fuzzy logic approach for estimation of permeability and rock type from conventional well log data: an example from the Kangan reservoir in the Iran Offshore gas field," Journal of Geophysics and Engineering, vol. 3, no. 4, pp. 356-369, 2006.

[35] A. Abdulraheem, E. Sabakhy, M. Ahmed, A. Vantala, P. D. Raharja, and G. Korvin, "Estimation of permeability from wireline logs in a middle eastern carbonate reservoir using fuzzy logic," in Proceedings of the SPE Middle East Oil and Gas Show and Conference. Society of Petroleum Engineers, Manama, Bahrain, March 2007.

[36] H. Kaydani, A. Mohebbi, and A. Baghaie, "Neural fuzzy system development for the prediction of permeability from wireline data based on fuzzy clustering," Petroleum Science and Technology, vol. 30, no. 19, pp. 2036-2045, 2012.

[37] T. D. Gedeon, P. M. Wong, Y. Huang et al., "Two dimensional fuzzy-neural interpolation for spatial data," Proceedings Geoinformatics, vol. 97, pp. 159-166, 1997.

[38] A. Wang, N. An, G. Chen, L. Li, and G. Alterovitz, "Accelerating wrapper-based feature selection with $k$-nearestneighbor," Knowledge-Based Systems, vol. 83, pp. 81-91, 2015.

[39] C. H. Park and S. B. Kim, "Sequential random $k$-nearest neighbor feature selection for high-dimensional data," Expert Systems with Applications, vol. 42, no. 5, pp. 2336-2342, 2015. 
[40] M. Popescu and J. M. Keller, "Random projections fuzzy $k$ nearest neighbor (RPFKNN) for big data classification," in Proceedings of the 2016 IEEE International Conference on Fuzzy Systems (FUZZ-IEEE), pp. 1813-1817, IEEE, Vancouver, Canada, July 2016.

[41] D. Qin, Z. Liu, H. Bai et al., "A new nano-engineered hierarchical membrane for concurrent removal of surfactant and oil from oil-in-water nanoemulsion," Scientific Reports, vol. 6, Article ID 24365, 2016.

[42] C. N. Papadimitriou, E. I. Zountouridou, and N. D. Hatziargyriou, "Review of hierarchical control in DC microgrids," Electric Power Systems Research, vol. 122, pp. 159-167, 2015. 